\title{
Correction to: Nuclear and Radiological Emergencies in Animal Production Systems, Preparedness, Response and Recovery
}

Ivancho Naletoski, Anthony G. Luckins, and Gerrit Viljoen

Correction to: I. Naletoski et al. (eds.), Nuclear and Radiological Emergencies in Animal Production

Systems, Preparedness, Response and Recovery, https://doi.org/10.1007/978-3-662-63021-1

This book was inadvertently published with the incomplete affiliation of the editors Ivancho Naletoski and Gerrit Viljoen, and the Foreword author Qu Liang. The correct affiliation is updated now as below:

Animal Production and Health Section

Joint FAO/IAEA Centre of Nuclear Techniques in Food and Agriculture

Department of Nuclear Sciences and Applications

International Atomic Energy Agency

Vienna International Centre, Vienna, Austria.

The updated version of the book can be found at https://doi.org/10.1007/978-3-662-63021-1 